\title{
Optimum distance for voice navigation in walking support system for visually impaired
}

\author{
Akinari Ohfuji ${ }^{1}$, Yoshihiro Taniura ${ }^{2}$, Dai Hanawa ${ }^{1,3}$ and Kimio Oguchi ${ }^{1,2, a}$ \\ ${ }^{1}$ Information Networking Laboratory, Faculty of Science and Technology, Seikei University, 180-8633 Tokyo, Japan \\ ${ }^{2}$ Information Networking Laboratory, Graduate School of Science and Technology, Seikei University, 180-8633 \\ Tokyo, Japan \\ ${ }^{3}$ Graduate School of Design and Architecture, Nagoya City University, 464-0083 Nagoya, Japan
}

\begin{abstract}
Voice navigation with information and communication technologies allows the visually impaired (VI) to grasp the current situation promptly. While instruction prior to the action e.g. turning a corner, seems to be effective, the optimum lead distance remains unclear. This paper verifies experimentally the optimum lead distance to support VI while walking. In the experiment, each subject (normal vision) walked while wearing an eye mask to simulate VI, holding a white cane, and received voice guidance. After each trial, the subject scored the lead distance in terms of acceptability. 28 young healthy males/females participated. Results showed the highest score was for $3 \mathrm{~m}$ while the lowest was for $5 \mathrm{~m}$. Distance range with score over 3 (average) was 2 to $4 \mathrm{~m}$. No clear significant difference was observed in terms of subject height. As walking speed was around $0.55 \mathrm{~m} / \mathrm{s}, 1 \mathrm{~m}$ was deemed insufficient. $5 \mathrm{~m}$ or more seemed to be too long as subjects failed to predict accurately how far they had moved. This experiment verified that VI voice navigation turn instructions are effective if given more than $1 \mathrm{~m}$ and less than $4 \mathrm{~m}$ before the turning point.
\end{abstract}

\section{Introduction}

Due to the spread of diabetic disease, the number of the visually impaired (VI) is increasing. As more than $80 \%$ of the information obtained by healthy people is generally derived from visual information [1], any vision impairment complicates daily life. The VI emphasizes the remaining senses of touching, hearing, smell and taste [1]. There are two main types; totally blind and partially blind. More than 285 million (M) people worldwide suffer from vision loss that interferes with daily activities. Among them, $39 \mathrm{M}$ are totally blind. In Japan, about $0.3 \mathrm{M}$ people are visually impaired and the number is increasing year by year [2].

Most VI use a white cane in daily life while walking outside the house, or inside of shopping malls/office buildings, however, its extremely limited range limits its effectiveness. Use of ICTs (Information and Communication Technologies) is an interesting and attractive solution [3]. As more of the VI are now using ICT devices such as tablet, smartphones [4], guidance systems based on such devices seemed effective.

\footnotetext{
${ }^{\text {a } C o r r e s p o n d i n g ~ a u t h o r ~: ~ o g u c h i @ s t . s e i k e i . a c . j p ~}$
} 


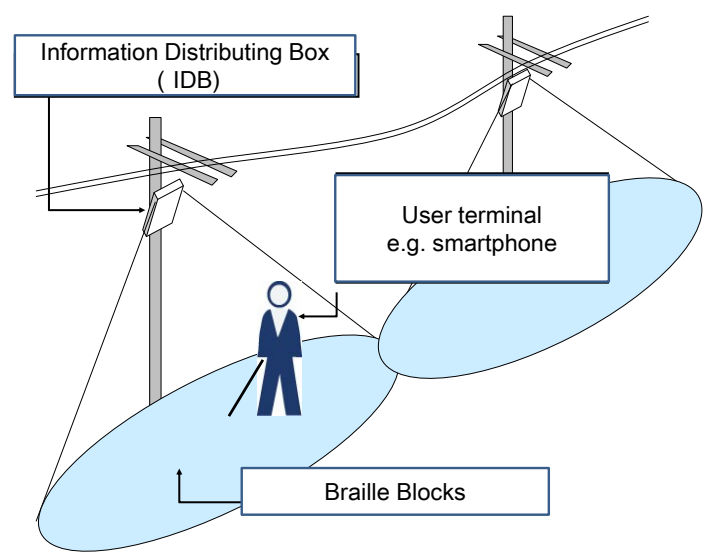

Figure 1. Proposed walking support system image on the street.

Many other researches are being performed. Some are as follows as: Voice guidance using information gathered from RFID (Radio Frequency Identification) tags embedded in braille blocks [5, 6]. Cloud base outdoor assistive navigation system [7]. A smart and intelligent cane developed that detects an object or obstacle using ultrasonic sensors and gives audio instructions for guidance [8]. Haptic feedback device and voice command used for moving freely realized by data captured through the Kinect device [9]. Make a warning through both voice and vibration when determine the range of obstacles by an ultrasonic device [10]. They all are systems based on voice navigation.

Voice navigation allows the VI to grasp the situation promptly. While instruction prior to the action e.g. turning a corner, seems to be effective, the optimum lead distance remains unclear. Therefore, this research verifies experimentally the optimum lead distance to support the walking VI.

The structure of this paper is as follows; Section 2 clarifies the final proposed VI walking support system with voice navigation. Section 3 describes the first experiment; it clarifies whether guidance that uses only distance is enough for voice navigation. In addition, it shows the importance of optimizing the lead distance for voice navigation, the subject of the second experiment. Section 4 describes outlined functional blocks for the future system image. Conclusion and future work are then given.

\section{Proposed system image}

The final target of this research, a VI walking support system, is shown in Fig. 1. VI walks with a mobile terminal device as smartphone or voice navigating terminal that can communicate with any information distribution box (IDB) located on street poles. Radio frequency (RF) signal is likely to be used for such communication. Brail blocks $[5,6]$ on the road might be another guidance technology them.

\section{Experiment}

\subsection{Lead distance information only (First experiment)}

\subsubsection{Experimental methodology}

The first experiment verifies whether just the lead distance is enough to assist the VI when walking.

The experiment proceeded as follows;

1-1. Each subject was told a distance to move (e.g. $3 \mathrm{~m}$ ) randomly prior to walking,

1-2. The subject walked straight ahead wearing an eye mask for the indicated distance, 
1-3. Each subject walked 15 times in total (5 different distances $\mathrm{x} 3$ times each), and

$1-4$. The distance actually walked was then compared the instructed distances.

The subjects were 11 young healthy people as listed in Table 1 . The experiment was performed in a corridor of the university.

Table 1. Attributes of 11 subjects: the first experiment.

\begin{tabular}{|c|c|c|c|}
\hline Subject & Gender & Age (year) & Height (m) \\
\hline $1 \mathrm{a}$ & male & 24 & 1.70 \\
\hline $1 \mathrm{~b}$ & male & 21 & 1.73 \\
\hline $1 \mathrm{c}$ & female & 19 & 1.53 \\
\hline $1 \mathrm{~d}$ & male & 22 & 1.75 \\
\hline $1 \mathrm{e}$ & male & 22 & 1.63 \\
\hline $1 \mathrm{f}$ & male & 19 & 1.78 \\
\hline $1 \mathrm{~g}$ & male & 22 & 1.75 \\
\hline $1 \mathrm{~h}$ & female & 20 & 1.60 \\
\hline $1 \mathrm{i}$ & male & 21 & 1.72 \\
\hline $1 \mathrm{j}$ & female & 21 & 1.55 \\
\hline $1 \mathrm{k}$ & male & 19 & 1.72 \\
\hline
\end{tabular}

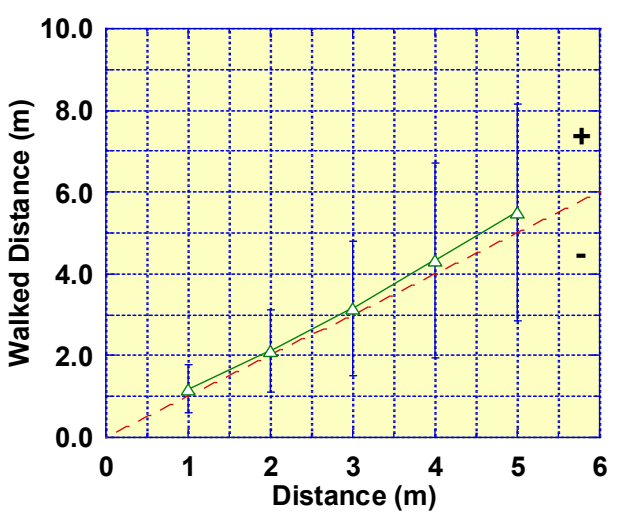

Figure 2. Results when only distance information was provided. Measured average values and deviations are

\subsubsection{Experimental results}

Figure 2 plots the average walked distance versus the instructed distances of 1, 2, 3, 4, and $5 \mathrm{~m}$, plus their standard deviations. Here, “+”means a subject walked longer than the instructed distance, while "_" indicates a shorter distance.

As seen in the figure, all subjects walked longer regardless of the distance and their deviations increased with distance. Distance perspective with eye mask, or accuracy of walked distance, depends strongly on the subject. For example, some subjects walked more than twice the required distance for 3,4 , and $5 \mathrm{~m}$. These results imply that a simple statement of distance is not enough for VI navigation assistance.

\subsection{The second experiment}

\subsubsection{Experimental methodology}

As the first experiment confirmed that just distance information is not enough, the second experiment used two voiced instructions.

The procedures are as follows; 
2-1. Each subject walked while holding a white cane (1.27 m length, folding type) while wearing an eye mask to simulate VI,

2-2. The subject received voice guidance such as "left turn is in $\mathrm{N} \mathrm{m}$ " at $\mathrm{N} \mathrm{m}$ before the corner, and then the instruction "turn left here" at the corner, as seen in Figure 3. $\mathrm{N}$ is 1, 2, 3, 4 and $5 \mathrm{~m}$,

2-3. After each trial, the subject evaluated the acceptability of the lead distance using scores of 1 to 5 (very bad, bad, average, good, and very good, respectively).

2-4. Each subject performed 3 trials for each N.

Subjects participating in the second experiment were 28 young healthy people whose attributes are listed in Table 2.

This experiment was performed in the same university corridor.
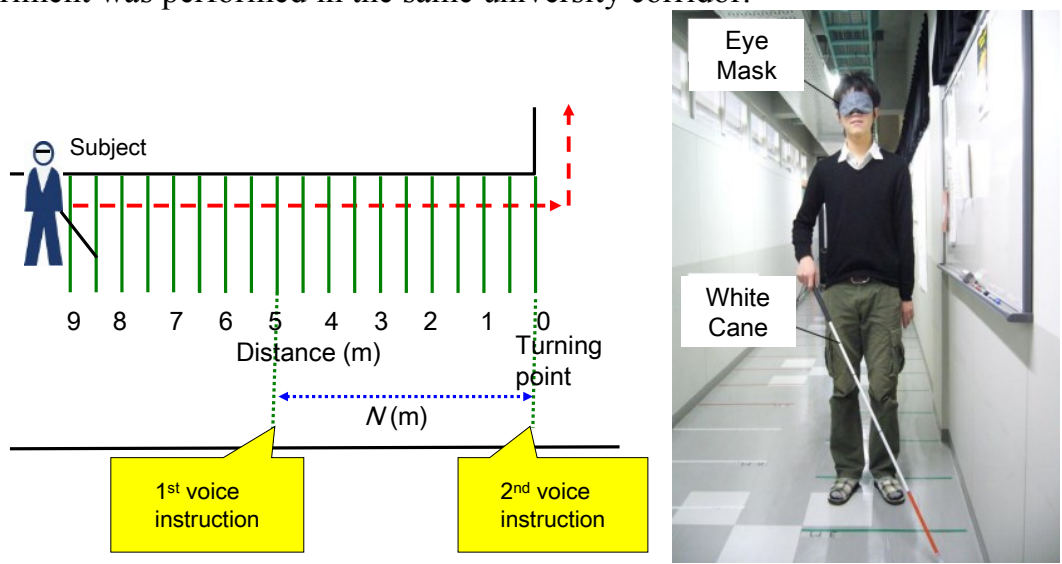

Figure 3. Experimental procedures (schematic view), and a photo of a subject walking with a white cane.

Table 2. Attributes of 28 subjects: second experiment.

\begin{tabular}{|c|c|c|c|c|}
\hline Subject & Gender & Age (year) & Height (m) & Foot size (cm) \\
\hline $2 \mathrm{a}$ & male & 20 & 1.65 & 25.0 \\
\hline $2 \mathrm{~b}$ & male & 20 & 1.71 & 26.5 \\
\hline $2 \mathrm{c}$ & female & 20 & 1.70 & 23.5 \\
\hline $2 \mathrm{~d}$ & female & 19 & 1.53 & 24.5 \\
\hline $2 \mathrm{e}$ & male & 20 & 1.67 & 26.5 \\
\hline $2 \mathrm{f}$ & male & 21 & 1.77 & 28.0 \\
\hline $2 \mathrm{~g}$ & male & 21 & 1.70 & 26.0 \\
\hline $2 \mathrm{~h}$ & male & 21 & 1.72 & 26.0 \\
\hline $2 \mathrm{i}$ & male & 22 & 1.75 & 28.0 \\
\hline $2 \mathrm{j}$ & male & 19 & 1.78 & 27.5 \\
\hline $2 \mathrm{k}$ & female & 20 & 1.60 & 24.0 \\
\hline $2 \mathrm{l}$ & male & 20 & 1.75 & 26.5 \\
\hline $2 \mathrm{~m}$ & male & 22 & 1.66 & 26.0 \\
\hline $2 \mathrm{n}$ & female & 21 & 1.60 & 23.5 \\
\hline $2 \mathrm{o}$ & female & 21 & 1.55 & 23.5 \\
\hline $2 \mathrm{p}$ & male & 19 & 1.64 & 27.0 \\
\hline $2 \mathrm{q}$ & male & 22 & 1.63 & 25.0 \\
\hline $2 \mathrm{r}$ & male & 22 & 1.63 & 26.0 \\
\hline $2 \mathrm{~s}$ & male & 19 & 1.74 & 27.0 \\
\hline $2 \mathrm{t}$ & male & 19 & 1.70 & 27.0 \\
\hline $2 \mathrm{u}$ & male & 19 & 1.61 & 27.5 \\
\hline $2 \mathrm{v}$ & male & 19 & 1.69 & 26.0 \\
\hline $2 \mathrm{w}$ & male & 19 & 1.75 & 26.0 \\
\hline $2 \mathrm{x}$ & male & 19 & 1.82 & 27.0 \\
\hline & & & & \\
\hline
\end{tabular}




\begin{tabular}{|c|c|c|c|c|}
\hline $2 \mathrm{y}$ & male & 19 & 1.66 & 27.0 \\
\hline $2 \mathrm{z}$ & male & 19 & 1.79 & 27.5 \\
\hline $2 \mathrm{aa}$ & male & 20 & 1.76 & 27.0 \\
\hline $2 \mathrm{ab}$ & male & 21 & 1.77 & 27.0 \\
\hline
\end{tabular}

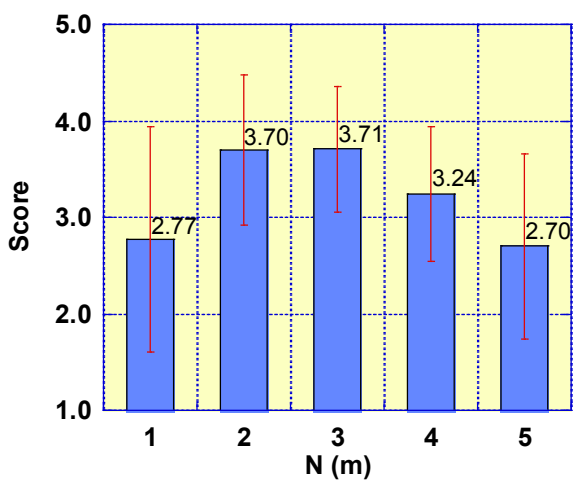

Figure 4. Measured results of the second experiment. Average score and its deviation (error bar) are depicted for the $\mathrm{N}$ values of $1,2,3,4$, and $5 \mathrm{~m}$.

\subsubsection{Results}

Figure 4 shows the results of average score for each $\mathrm{N}$ and its deviation. Highest score (3.71) was for $\mathrm{N}=3 \mathrm{~m}$ while the lowest (2.70) was for $5 \mathrm{~m}$. Distance range with score over 3 (average) was 2 to $4 \mathrm{~m}$.

The significant difference in the results was identified and analyzed. The sign test found a significant difference between $\mathrm{N}=3$ and 4 , and between $\mathrm{N}=3$ and 5 . These results indicate that preferred lead distance is $1<\mathrm{N}<4 \mathrm{~m}$. As walking speed was around $0.55 \mathrm{~m} / \mathrm{s}, \mathrm{N}=1$ (around $2 \mathrm{sec}$ ) was deemed insufficient. $\mathrm{N}=5$ or more seemed to be too long as subjects failed to predict accurately how far they had moved.

Dependency on height was also analyzed using two groups, one with height of $1.60 \leqq \mathrm{~h}<1.70 \mathrm{~m}$, and the other with $1.70 \leqq \mathrm{~h}<1.80 \mathrm{~m}$ (gender neutral). Here, all data were separated into the two groups and analyzed.

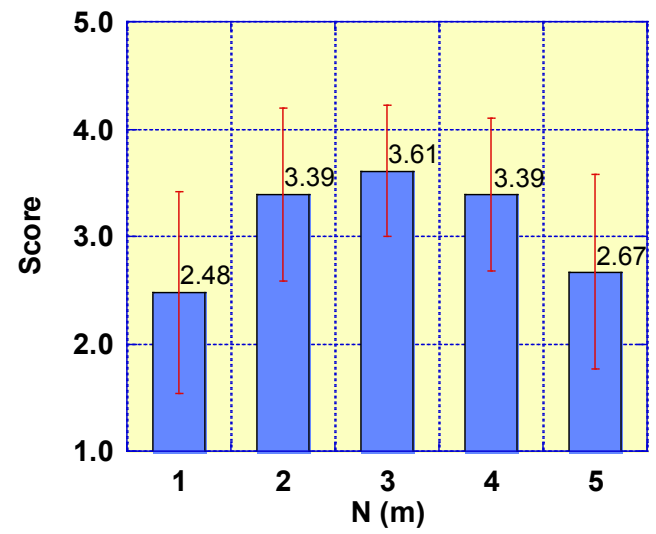

Figure 5. Measured results for the shorter group: average score for each $\mathrm{N}$ and its deviation.

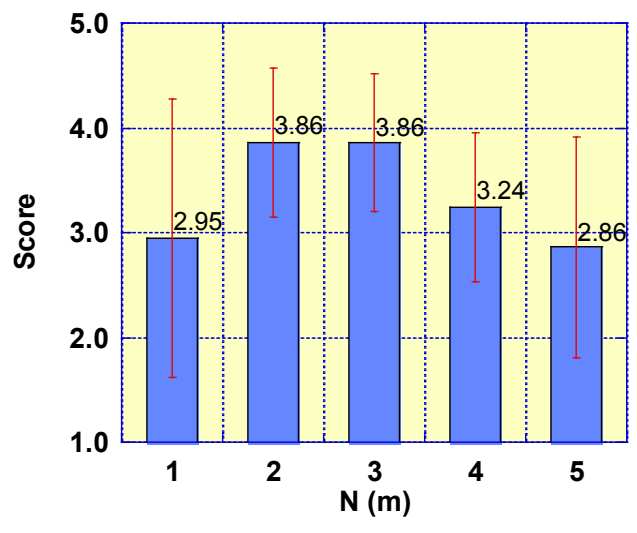

Figure 6. Measured results for the taller group: average score for each $\mathrm{N}$ and its deviation.

Figure 5 shows the results for the shorter group with average score for each $\mathrm{N}$ and its deviation. Highest score (3.61) was for $\mathrm{N}=3 \mathrm{~m}$ while the lowest (2.48) was for $1 \mathrm{~m}$. Distance range with score over 3 (average) was the same, 2 to $4 \mathrm{~m}$. No significant difference was observed. These results indicate that preferred lead distance is $1<\mathrm{N}<5 \mathrm{~m}$. 
Figure 6 shows the results for the taller group with average score for each $\mathrm{N}$ and its deviation. Highest score (3.86) was for $\mathrm{N}=2$ and $3 \mathrm{~m}$ while the lowest (2.86) was for $5 \mathrm{~m}$. Distance range with score over 3 (average) was the same, 2 to $4 \mathrm{~m}$. These results indicate that preferred lead distance is $1<$ $\mathrm{N}<5 \mathrm{~m}$. With the sign test, a significant difference was observed between $\mathrm{N}=2$ and 1 , and between $\mathrm{N}=3$ and 1 , between 3 and 4 , and between 3 and 5 . These results indicate that $\mathrm{N}=1,4$, and 5 have significant differences. Therefore, the preferred lead distance is more than $1 \mathrm{~m}$ and less than $4 \mathrm{~m}$.

This analysis of subject height dependency shows that it is small, if it exists. Therefore, the preferred lead distance is more than $1 \mathrm{~m}$ and less than $4 \mathrm{~m}$ for all body heights.

\section{Outlined functional blocks}

Figure 7 shows outlined functional blocks for the VI supporting system (see Figure 1) where the administration manages information distributing boxes (IDBs) via network. VI requests e.g. location information to the nearest IDB, and then the information is provided through a wearable device. Home of the VI provides the path information to be planned and knows the current location via network. The wearable device may use the GPS (Global Positioning System) information.

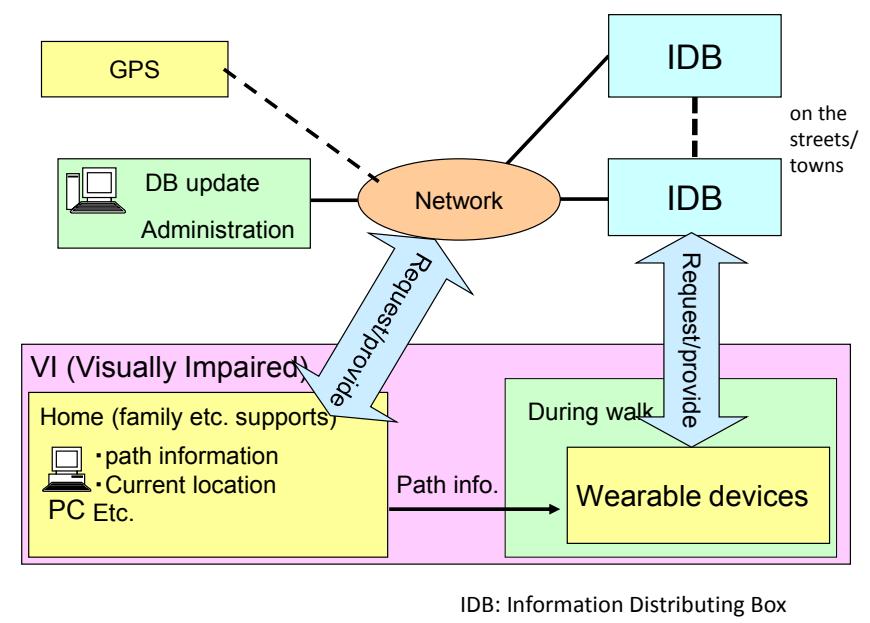

Figure 7. Outlined functional blocks for VI supporting system.

\section{Conclusion}

In order to realize a more effective walking support system with voice navigation for the visually impaired, we experimentally examined the optimum lead distance for voiced movement (distance) instruction.

The first experiment clarified that simply providing just distance information once is not enough to realize effective voice navigation. The second experiment examined the effectiveness of two voice instructions. A total of 28 subjects simulated the movements of the visually impaired and scored the preferred distance. These experiments verified that VI voice navigation is effective if the distance instruction is given more than $1 \mathrm{~m}$ and less than $4 \mathrm{~m}$ before the turning point. No clear significant difference was observed in terms of subject height.

Future work includes an experiment with actual VIs to clarify how different they are and for other case e.g. at the step, and development of a more comprehensive guidance system.

\section{References}

1. M. Tsuda, When the visually impaired walk around the city (Toshi Publication, 1999) 
2. Government of Japan, Status of persons with disabilities, http://www8.cao.go.jp/shougai/whitepaper/h25hakusho/zenbun/furoku_08.html

3. Z. Farid, R. Nordin and M. Ismail, Journal of Computer Networks and Communications, 2013, 1$12(2013)$

4. T. Watanabe, T. Yamaguchi and K. Minatani, A Survey on the Use of Mobile Phones, Smartphones, Tablets, Personal Computers by Blind and Visually Impaired Persons 2013, The Telecommunications Advancement Foundation, The study Investigation Grant Achievement Report (2014)

5. NPO Kotoba no Michiannai, Tokyo Metropolitan Government Bureau of Construction, Experiment of a guide system for the visually impaired in Tokyo, https://www.hido.or.jp/14gyousei_backnumber/2011data/1111/1111kotonavi-metro.pdf

6. Japanese Industrial Standard, JIS T9251:2014, Guidelines for older persons and persons with disabilities -- Shapes, dimensions and patterns of raised parts of tactile walking surface indicators for persons who are blind or with seeing impairment (2014)

7. A. N. Lapyko, L-P. Tung and B-S. P. Lin, 2014 7th IFIP Wireless and Mobile Networking Conference (WMNC), 1-8 (2014)

8. A. Noorithaya, M.K. Kumar and A. Sreedevi, International Conference on Circuits, Communication, Control and Computing, 177-181 (2014)

9. F. Ahmad, Tanveerulhaq, I. Ishaq, D. Ali and M. F. Riaz, 2016 International Conference on Bioengineering for Smart Technologies (BioSMART), 1-4 (2016)

10. N. Mahmud, R.K. Saha, R.B. Zafar, M.B.H. Bhuian and S.S. Sarwar, 2014 International Conference on Informatics, Electronics \& Vision (ICIEV), 1-5 (2014) 